\title{
Medical Clearance
}

National Cancer Institute

\section{Source}

National Cancer Institute. Medical Clearance. NCI Thesaurus. Code C148040.

Written permission from a medical professional stating that an individual is healthy enough to participate in a specific activity. 